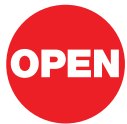

SUBJECT AREAS:

ATMOSPHERIC

DYNAMICS

ENVIRONMENTAL SCIENCES

PHYSICAL OCEANOGRAPHY

IMPACTS

Received

20 August 2012

Accepted

5 December 2012

Published

23 January 2013

Correspondence and requests for materials should be addressed to R.-H.Z. (rzhang@essic. umd.edu)

\section{A successful real-time forecast of the 2010-11 La Niña event}

\author{
Rong-Hua Zhang ${ }^{1,2}$, Fei Zheng ${ }^{3}$, Jiang Zhu ${ }^{3}$ \& Zhanggui Wang ${ }^{4}$
}

${ }^{1}$ Earth System Science Interdisciplinary Center (ESSIC), University of Maryland, College Park, Maryland, USA, ${ }^{2}$ College of Global Change and Earth System Science, Beijing Normal University, Beijing, China, ${ }^{3}$ International Center for Climate and Environment Science (ICCES), Institute of Atmospheric Physics, Chinese Academy of Sciences, Beijing, China, ${ }^{4}$ National Marine Environmental Forecasting Center, State Oceanic Administration, Beijing, China.
During 2010-11, a La Niña condition prevailed in the tropical Pacific. An intermediate coupled model (ICM) is used to demonstrate a real-time forecast of sea surface temperature (SST) evolution during the event. One of the ICM's unique features is an empirical parameterization of the temperature of subsurface water entrained into the mixed layer $\left(\mathrm{T}_{\mathrm{e}}\right)$. This model provided a good prediction, particularly of the "double dip" evolution of SST in 2011 that followed the La Niña event peak in October 2010. Thermocline feedback, explicitly represented by the relationship between $T_{e}$ and sea level in the ICM, is a crucial factor affecting the second cooling in 2011. Large negative $\mathrm{T}_{e}$ anomalies were observed to persist in the central equatorial domain during 2010-11, inducing a cold SST anomaly to the east during July-August 2011 and leading to the development of a La Niña condition thereafter.

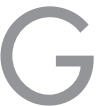
reat efforts have been made to develop and improve models of the El Niño-Southern Oscillation (ENSO). These models have been routinely used to predict sea surface temperature (SST) conditions in the tropical Pacific $^{1}$; see the International Research Institute for Climate and Society (IRI) website at: http://iri. columbia.edu/climate/ENSO/currentinfo/SST_table.html. Many of these ENSO predictions were made after the development of the first dynamic model at Columbia University in the mid-1980 $\mathrm{s}^{2,3}$. In the decades that followed, various models have been developed to improve the early ENSO predictions $s^{4-15}$.

Presently, more than 20 models are routinely used to make real-time forecasts of SST in the equatorial Pacific (e.g., see the details at the IRI website). During the period 2010-11, the tropical Pacific experienced a prolonged cold condition, with a second cooling at the sea surface that occurred in the fall of 2011. Figs. 1-2 illustrate observed anomaly fields and their horizontal structure and space-time evolution over the equator during 201112. A moderate-to-strong La Niña episode prevailed in 2010, which seemed to end in the spring of 2011 (see the Tropical Atmosphere Ocean (TAO) real-time data online at http://www.pmel.noaa.gov/tao/). Indeed, neutral SST conditions appeared during April-July 2011 in the eastern equatorial Pacific and were maintained until early August 2011, when weak La Niña conditions re-emerged. The strength of these conditions increased to weak/ moderate intensity during November 2011. A striking feature observed here was the appearance of a second cooling at the sea surface in the boreal fall of 2011.

However, most models have failed to forecast the Niño 3.4 SST from initial conditions in early-mid 2011; see the NOAA/NWS Science and Technology Infusion Climate Bulletin website at http://www.nws.noaa.gov/ost/ climate/STIP/r2o +o2r.htm. Yet, one intermediate coupled model (an ICM operated at ESSIC/UMD, the socalled ESSIC ICM) provided a good prediction of the 2011 cold SST conditions in the tropical Pacific (see Methods: An intermediate coupled model). In this report, the performance of the ESSIC ICM at predicting real-time SST evolution is analyzed to explore why this model correctly predicted what is called a "double dip" evolution of SST in mid-to-late 2011.

\section{Results}

Large thermal anomalies existed at subsurface depths in the tropical Pacific during 2010-11. For example, during the 2010 La Niña event, positive heat content was accumulated in the western equatorial region, which was observed to extend eastward along the equator, acting to weaken the cold SST anomalies in the east during the spring of 2011. This pattern was clearly evident in June 2011, when a neutral condition appeared in the eastern equatorial Pacific (Fig. 1). At this time, however, negative subsurface anomalies persisted in the central basin, with a maximum to the south of the equator. Additionally, large negative SL anomalies were observed to propagate westward off the equator in association with the first major cooling event, which peaked in October 2010. The 


\section{Observation}

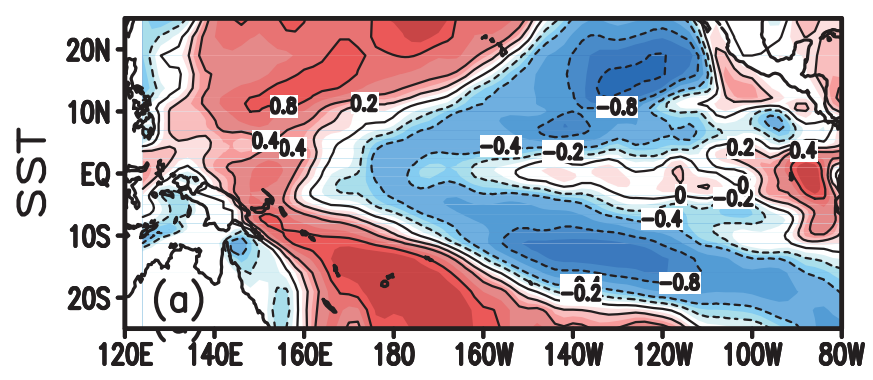

Model Initial States

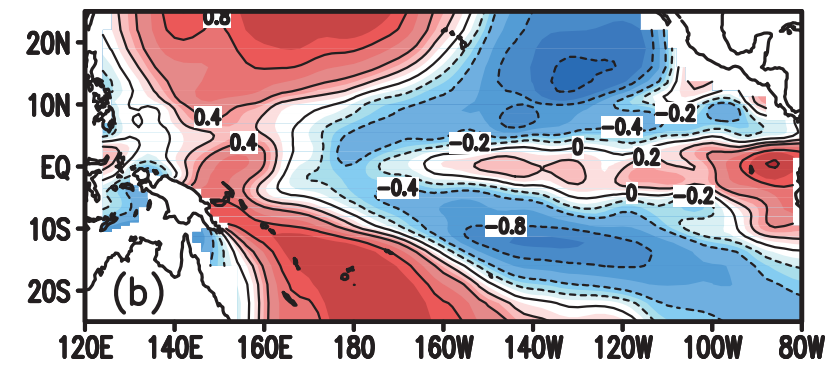

$-1.8-1.4-1-0.8-0.6-0.4-0.3-0.2-0.1$
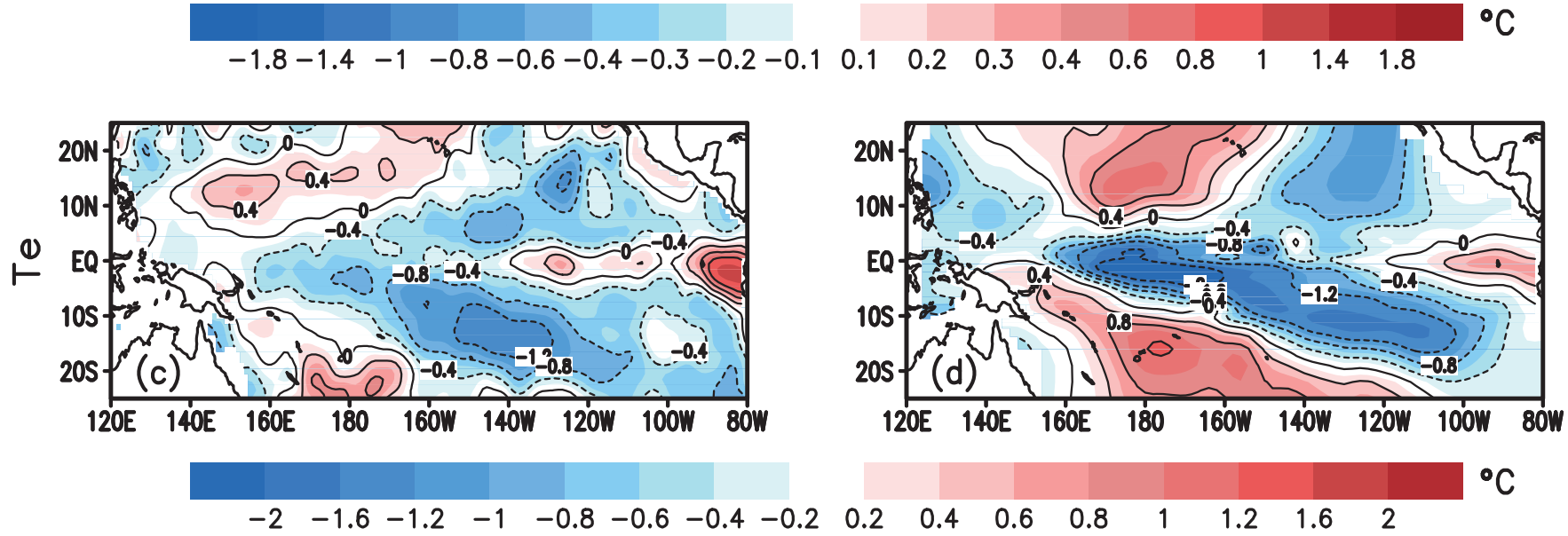

Figure 1 Horizontal distributions of SST and $\mathrm{T}_{\mathrm{e}}$ anomalies in the tropical Pacific. The left panels show the monthly-mean fields observed from ARGO-based data in May 2011, and the right panels show the instant fields on 1 June 2011 derived from the ICM initialization. The contour interval varies for SST (from $0.2^{\circ} \mathrm{C}$ to $0.4^{\circ} \mathrm{C}$ ) and is $0.4^{\circ} \mathrm{C}$ for $\mathrm{T}_{\mathrm{e}}$.

structure and evolution of these subsurface thermal anomalies can be well represented by the $\mathrm{T}_{\mathrm{e}}$ field, which exhibited a slight phase lead and larger variability amplitude compared with the SST in the central equatorial Pacific (Fig. 1).

Forecasts of SL, $\mathrm{T}_{\mathrm{e}}$ and SST fields using the ICM are presented in Fig. 2, which were made from initial conditions on 1 June 2011. Compared with the corresponding observations, the relationships between SL, $\mathrm{T}_{\mathrm{e}}$ and SST are well captured by the model. In particular, the ICM can predict interannual SST anomalies at lead times of 6 months and longer, capturing the second cooling event in the summer and fall of 2011. As we trace the SST evolution in the ICM prediction, it is found that the $T_{e}$ structure and evolution are crucial factors affecting SST variability. Some detailed analyses are given below.

The structure of $\mathbf{T}_{\mathbf{e}}$. Fig. 3 presents the horizontal distributions of $\mathrm{T}_{\mathrm{e}}$ anomalies during June-October 2011, which are predicted using the ICM from initial conditions on 1 June 2011 (Fig. 1). In the western equatorial region, positive $\mathrm{T}_{\mathrm{e}}$ anomalies prevailed during 2010-11. In the central equatorial Pacific, large negative $T_{e}$ anomalies were observed to persist throughout 2010-11, with a horseshoe-like pattern connecting subsurface variability off and on the equator. A few processes tended to sustain this $\mathrm{T}_{\mathrm{e}}$ pattern. On the atmospheric side, easterly wind anomalies were present near and west of the date line during 2010-11, acting to elevate the thermocline and give rise to negative $\mathrm{T}_{\mathrm{e}}$ anomalies in the central domain. On the oceanic side, negative subsurface thermal anomalies off the equator were observed to emerge onto the equator in the central basin, fostering the negative $\mathrm{T}_{\mathrm{e}}$ anomalies on the equator. Additionally, during and after the major La Niña event in 2010, negative SL anomalies were observed to propagate westward off the equator; their extension into the central equatorial region acted to reinforce the negative $\mathrm{T}_{\mathrm{e}}$ anomalies in the central basin.
Some discrepancies are also evident in this ICM calculation. For example, the amplitude of the simulated cold SST anomalies was too strong during 2010-11, which can be attributed to the calculated $\mathrm{T}_{\mathrm{e}}$ field whose negative anomalies were too large in the central equatorial Pacific (Fig. 2 and Fig. 3). Additionally, the $\mathrm{T}_{\mathrm{e}}$ forecast is not in agreement with the observations in the eastern equatorial Pacific, where significant warm anomalies were observed but not predicted by the model (Fig. 2). In addition, the simulated easterly wind anomalies in June-July 2011 were apparently weak over the central equatorial Pacific (Figs. 3f-g).

The dominant effects of the negative $T_{e}$ anomalies sustained in the central equatorial Pacific. During the 2010 La Niña event, positive thermal anomalies accumulated at subsurface depths in the western tropical Pacific, as represented by a positive $T_{e}$ anomaly, were observed to extend eastward along the equator, exerting an influence on the SST to the east. Indeed, the eastward propagation of the positive $\mathrm{T}_{\mathrm{e}}$ anomalies in April-June 2011 acted to weaken the cold SST anomalies in the east and to exhibit a tendency to reverse the La Niña phase. As a result, a neutral SST condition emerged in the eastern equatorial Pacific in mid-2011 (Figs. 3f-g). Additionally, large negative $\mathrm{T}_{\mathrm{e}}$ anomalies were present in the central-eastern equatorial basin during this period (Figs. 3a-b). These anomalies tended to block the eastward penetration of the positive $T_{e}$ anomalies from west to east on the equator. Moreover, the negative $\mathrm{T}_{\mathrm{e}}$ anomalies were observed to initiate a surface cooling in the central basin in July 2011 (Fig. 3 g), which further induced responses of easterly wind anomalies (Fig. $3 \mathrm{~h}$ ), leading to a coupling between the ocean and atmosphere. As a result, a weak La Niña condition re-emerged over the tropical Pacific in the fall of 2011 (Figs. 3i-j).

Thus, the fate of the SST evolution in the eastern equatorial Pacific in mid-2011 appeared to be determined by these two processes in a 

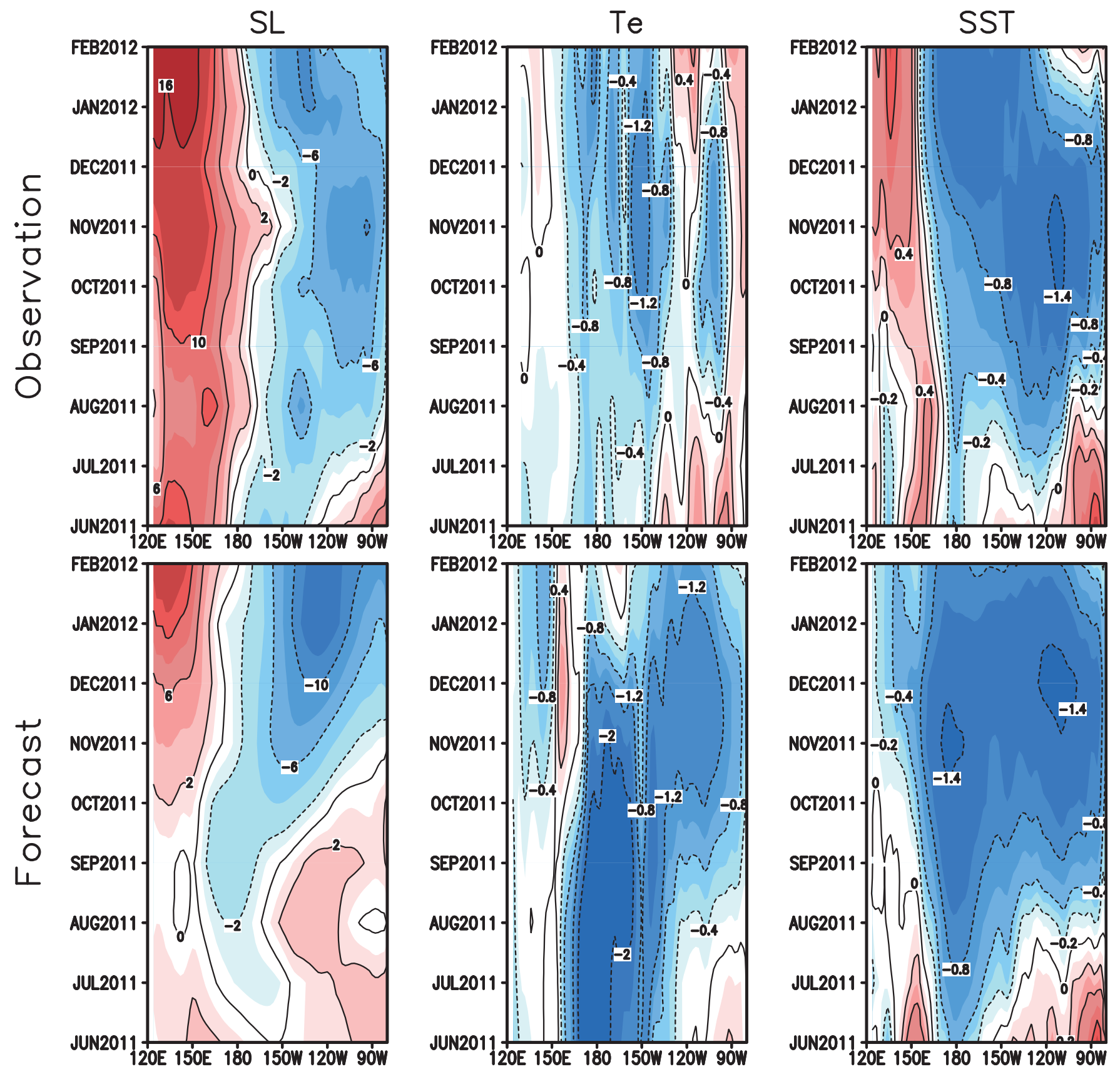

Figure $2 \mid$ Zonal-time sections of anomaly fields along the equator during the period Jun.2011-Feb. 2012 observed (the upper panels) and forecasted (the lower panels) using the ICM from an initial condition on 1 June 2011. The left column for SL, the middle column for $\mathrm{T}_{\mathrm{e}}$, and the right column for SST, respectively. The contour interval varies for SL (from 2 to $4 \mathrm{~cm}$ ), for $\mathrm{T}_{\mathrm{e}}$ (from 0.4 to $0.6^{\circ} \mathrm{C}$ ), and for SST (from 0.2 to $0.4^{\circ} \mathrm{C}$ ).

competing way. The positive heat content accumulated in the west during 2010, with its eastward propagation along the equator, tended to have a warming effect on the SST to the east, while the persistent negative $\mathrm{T}_{\mathrm{e}}$ anomalies in the central equatorial domain, sustained by off-equatorial variability, acted to exert a cooling influence. The fact that the SSTs in the east cooled in August 2011 indicates that the cooling effect of the negative $\mathrm{T}_{\mathrm{e}}$ anomalies played a dominant role in the double-dip evolution of the SST in 2011 and that the warming effect of the positive heat content in the west was not sufficiently strong to reverse the cold condition associated with the major 2010 La Niña event.

Model prediction of the SST evolution. Fig. 4 further presents the predicted Niño 3.4 SST anomalies for 2011-12. It is clearly evident that the ICM can, at lead times of 6 months and more, depict the two turning points of the observed SST evolution: one in June 2011, from warming to cooling, and other in January 2012, from cooling to warming, respectively. The onset and evolution of the second cooling in the fall of 2011 are predicted particularly well. For example, the model forecasts followed the corresponding observations very closely. In early 2011, the La Niña condition was decaying, and SSTs became near normal in mid-July; a return of La Niña conditions occurred in the fall of 2011, which continued into early 2012 when the SST evolution was observed to undergo another turn to warming in the tropical Pacific.

Sensitivity experiments. The thermocline structure and variability in the tropical Pacific are well known to play an important role in the ENSO evolution; the related effects are referred to as thermocline feedback ${ }^{16}$. In the ICM we use (see Methods: An intermediate 
(a) Jun 2011

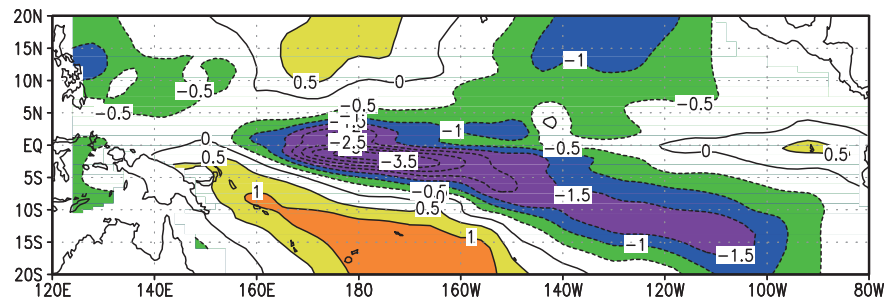

(b) Jul 2011

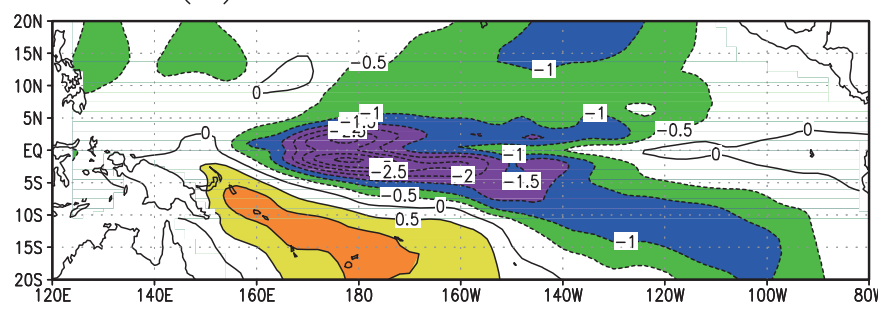

(c) Aug 2011

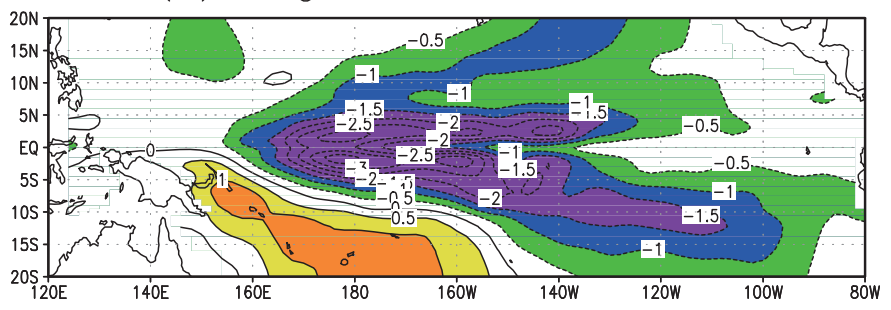

(d) Sep 2011

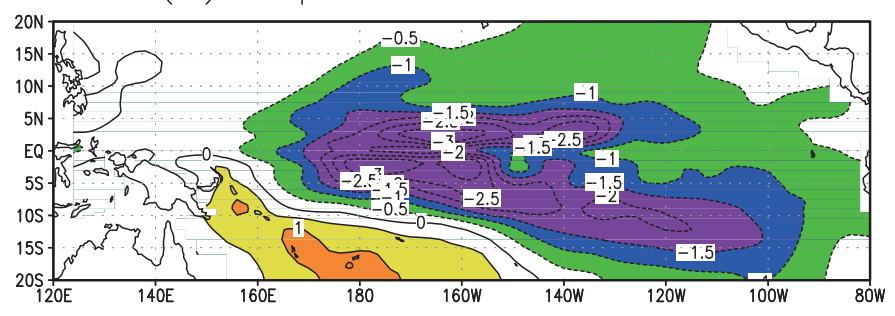

(e) Oct 2011

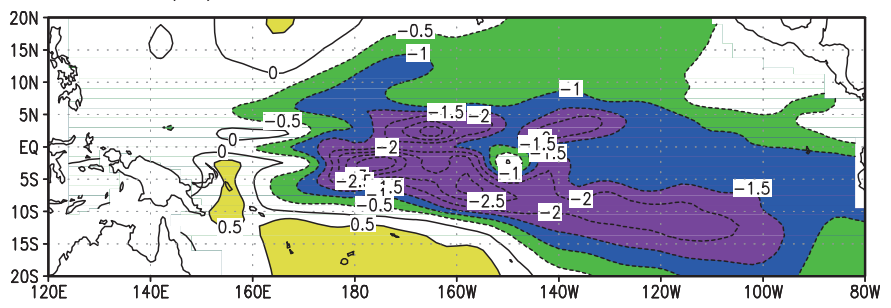

SST

(f) Jun 2011

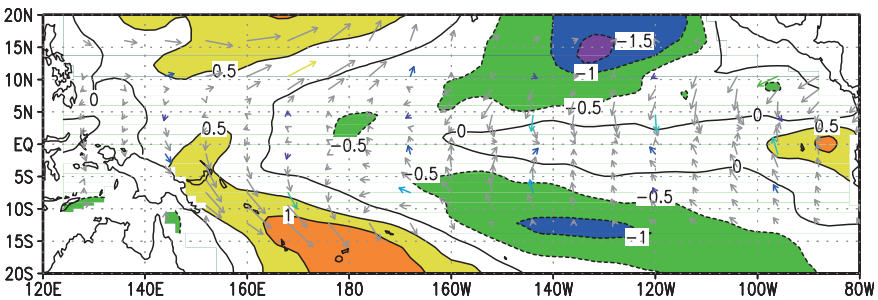

(g) Jul 2011

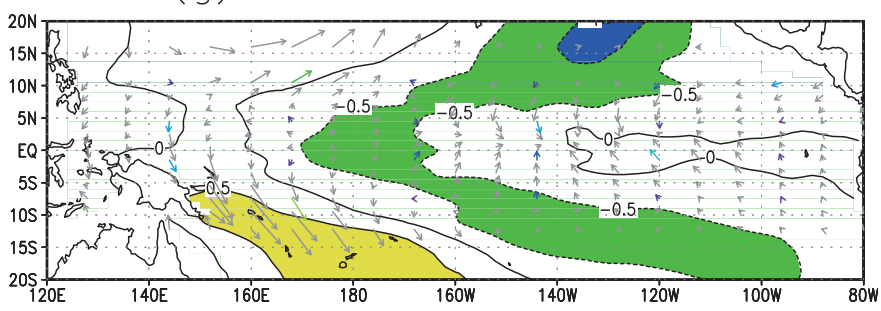

(h) Aug 2011

$\overrightarrow{0.6}$

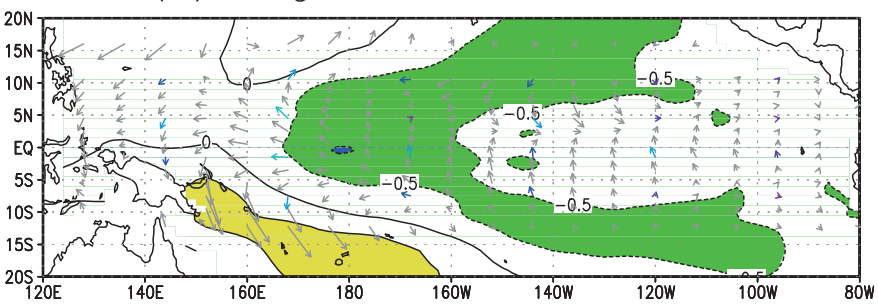

(i) Sep 2011

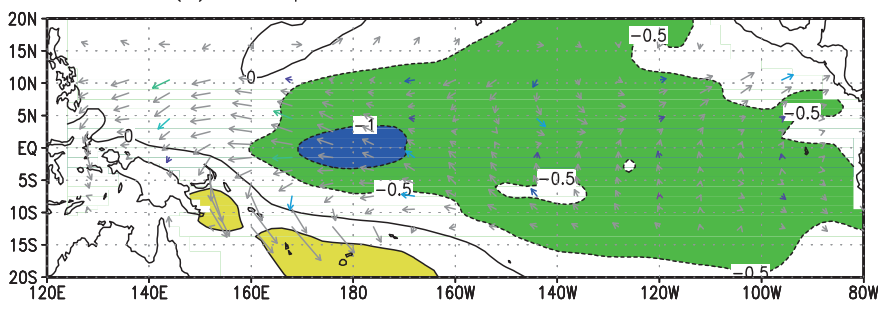

(j) Oct 2011

$\overrightarrow{0.6}$

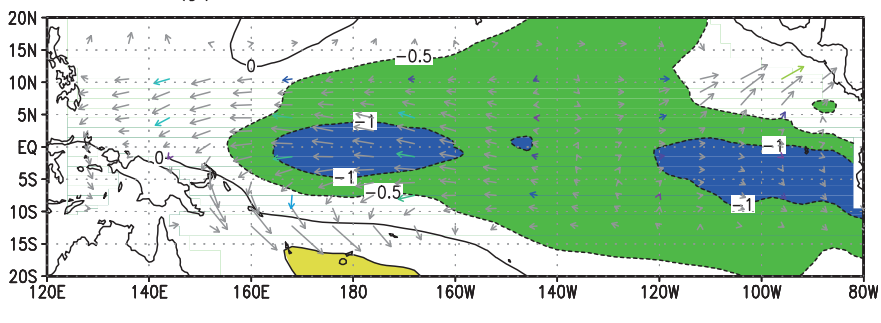

$\overrightarrow{0.6}$

Figure 3 Horizontal distributions of $\mathrm{T}_{\mathrm{e}}$ (the left panels) and SST (the right panels) anomalies during the period June-October 2011, which are predicted using the ICM from the initial condition on 1 June 2011. Overlaid on the SST fields are the corresponding wind stress anomalies. The contour interval is $0.5^{\circ} \mathrm{C}$ for $\mathrm{T}_{\mathrm{e}}$ and SST, and the unit for wind stress is dyn $\mathrm{cm}^{-2}$.

coupled model), this effect is explicitly represented by the relationships between $\mathrm{T}_{\mathrm{e}}$ and SL, which are empirically derived from historical data ${ }^{17}$, written as $\mathrm{T}_{\mathrm{e}}=\alpha_{\mathrm{Te}} \cdot \mathrm{F}_{1}(\mathrm{SL})$. The parameter $\alpha_{\mathrm{Te}}$ is introduced to represent the thermocline feedback strength; a change in $\alpha_{\mathrm{Te}}$ acts to modulate the relationships between $\mathrm{T}_{\mathrm{e}}$ and the thermocline variability and, thus, their effect on SST. As such, the ICM performance in terms of ENSO simulation and prediction is expected to depend on the thermocline feedback intensity, as represented by this parameter.

Fig. 5 illustrates the sensitivity of the SST predictions to $\alpha_{\mathrm{Te}}$, which again shows that the second cooling event in 2011 can be well predicted, even from initial conditions in early 2011. The changes in $\alpha_{\mathrm{Te}}$ have direct effects on the phase transition and amplitude of SST variability. The larger the $\alpha_{\mathrm{Te}}$, the stronger the thermocline feedback 


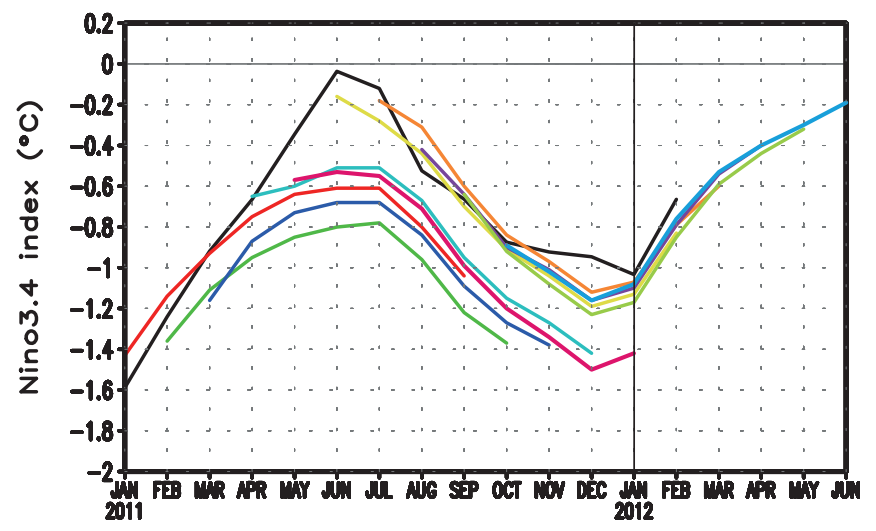

Figure $4 \mid$ Observed (black line) and predicted (colored lines) Niño 3.4 SST anomalies (averaged over the region $\left(5^{\circ} \mathrm{S}-5^{\circ} \mathrm{N} ; 170^{\circ} \mathrm{W}-120^{\circ} \mathrm{W}\right)$ ) for the years 2011-12. Each colored line indicates the trajectory of a 12-month forecast made using the ICM from different initial conditions (the first day of each month).

represented and the larger the amplitude of the predicted SST anomalies. In particular, when the thermocline feedback intensity is increased to a certain level, a second cooling period emerges, which is sustained for a longer period and is stronger in 2011. Additionally, the increase in $\alpha_{\mathrm{Te}}$ exhibits modulating effects on the phase shift from one state to another. In contrast, when $\alpha_{\mathrm{Te}}$ is reduced, the thermocline feedback intensity is weakly represented. The resultant negative $\mathrm{T}_{\mathrm{e}}$ anomalies in the central equatorial Pacific become weak, leading to effects on the SST that are also weak. In particular, if the thermocline feedback intensity is represented weakly below certain levels (say $\alpha_{\mathrm{Te}}<0.5$ ), the second cooling could not occur in 2011; instead, a surface warming emerges in 2011, with weak SST variability.

These experiments clearly illustrate that ENSO predictions are sensitively dependent on the way the thermocline feedback intensity is adequately depicted, which is explicitly represented by the relationships between $\mathrm{T}_{\mathrm{e}}$ and SL in the ICM $\left(\alpha_{\mathrm{Te}}\right)$. In particular, the strength and persistence of the negative $\mathrm{T}_{\mathrm{e}}$ anomalies in the central equatorial domain are crucially important to the second cooling in 2011. These simplified modeling results also indicate that the explicitly determined $\mathrm{T}_{\mathrm{e}}$ field in the ICM and its empirical parameterization derived from historical data provide a way in which ENSO predictions can be improved effectively. For example, $\alpha_{\mathrm{Te}}$ can be conveniently used to tune the $\mathrm{T}_{\mathrm{e}}$-SL relationships and, thus, the thermocline feedback intensity so that the best model forecasts can be produced, as demonstrated in Fig. 5.

\section{Discussion}

A moderate-to-strong La Niña episode prevailed in the tropical Pacific in 2010 and was decaying and seemingly ending in early May 2011. This episode was followed by a neutral SST condition until early August, when surface cooling occurred again and gradually strengthened. Surface cooling continued to sustain a weak La Niña condition through early 2012. At subsurface depths, large negative thermal anomalies persisted in the central equatorial domain during 2010-11, characterized by a horseshoe-like pattern connecting subsurface variability off and on the equator. This pattern tended to effectively inhibit the eastward propagation of subsurface warm anomalies accumulated in the west along the equator in early 2011. Moreover, the sustained negative Te anomalies in the central equatorial basin initiated a cold SST anomaly in the east during JulyAugust 2011, inducing atmospheric wind responses and oceanatmosphere coupling, which led to the development of a La Niña condition in the fall of 2011.

In this report, an ICM is used to make real-time SST forecasts during 2010-11, with a focus on oceanic processes that could be responsible for the second cooling in 2011 that followed the La Niña event in 2010. Because the ICM can accurately depict the related processes and relationships among anomaly fields $\left(\mathrm{SL}, \mathrm{T}_{\mathrm{e}}\right.$ and SST), a good prediction is achieved, particularly of what is called the "double dip" evolution of the SST in 2011. Analyses of the ICM forecasts indicate that thermocline feedback is critically important to interannual SST evolution, which is explicitly represented by the $\mathrm{T}_{\mathrm{e}}-\mathrm{SL}$ relationships in the ICM. Additional sensitivity experiments are further conducted to demonstrate the extent to which the SST forecasts are affected by the thermocline feedback. It is illustrated that the thermocline feedback intensity in a coupled model should be

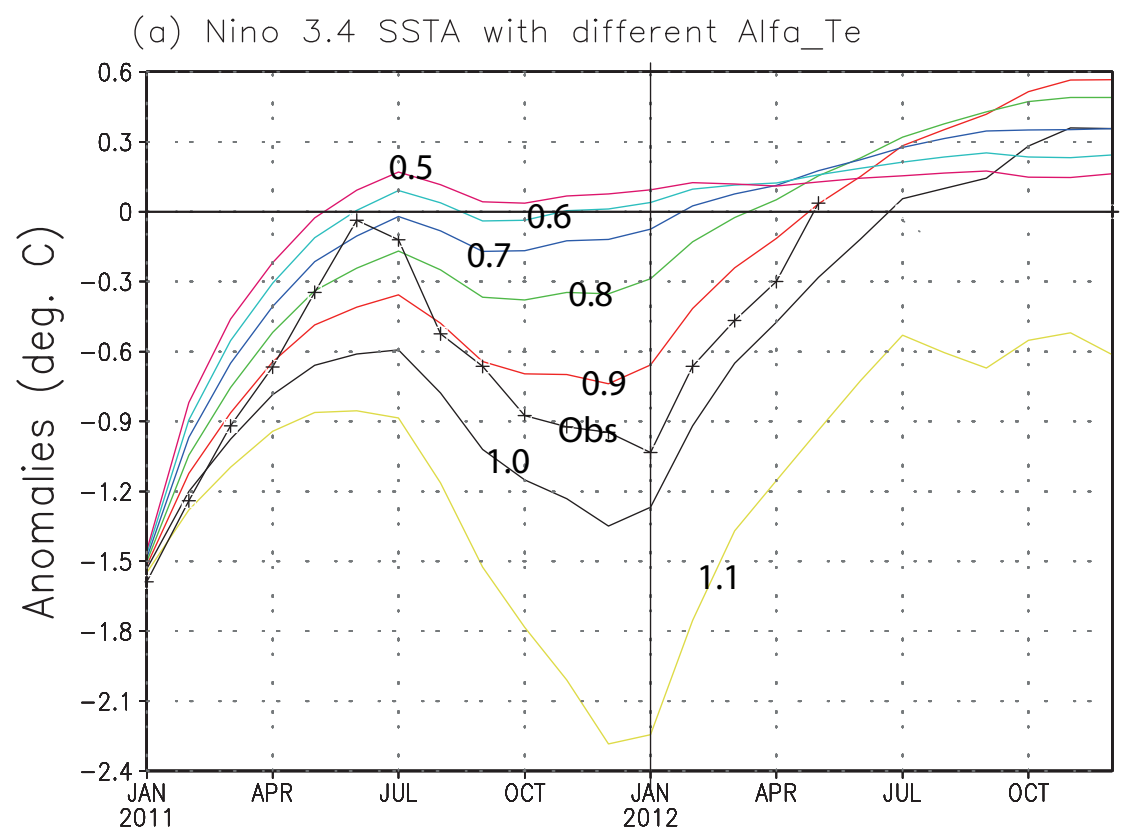

Figure 5 The Niño 3.4 SST anomalies during the years 2011-12, observed (black line with plus symbol) and predicted using the ICM from the initial condition on 1 January 2011. Each prediction line indicates the trajectory of a 24-month forecast made with different values of $\alpha_{\mathrm{Te}}$ ranging from $\alpha_{\mathrm{Te}}=0.5$ to $\alpha_{\mathrm{Te}}=1.1$, respectively. 
represented at certain levels to depict the second SST cooling in the fall of 2011.

Further modeling studies are underway to better characterize the double dip evolution of SST that was observed in 2011. In addition to the important role the explicit $\mathrm{T}_{\mathrm{e}}$ parameterization in the ICM based on the relation with SL plays in the SST evolution, pronounced easterly wind anomalies are also observed to persist over the central equatorial basin in early 2011, which indicates that atmospheric processes may also have a direct effect on the ocean. Further analyses are clearly necessary to examine the relative roles of these oceanic and atmospheric processes in the second cooling of the SST. In addition, inspection of the historical ENSO evolution indicates that other double-cooling cases have occurred in the tropical Pacific, including one in 1998-99. The similarity and differences among these events need to be analyzed to characterize the nature of these strikingly different ENSO evolutions and their possible decadal variabilities and modulations associated with various forcings and feedbacks within the Pacific climate system ${ }^{22-30}$.

At present, significant diversity and uncertainty still exist in ENSO predictions from different models. For example, along with this ICM, more than 20 other models are used for real-time ENSO prediction. Because most model forecasts are biased in the direction of SST evolution during the spring of 2011, they fail to predict the second cooling event in 2011. Given the accuracy of this ICM relative to other models, what are the specific "missing mechanisms" characteristic of other models? As shown in the sensitivity experiments, the second SST cooling in 2011 could not be captured if the thermocline feedback intensity was represented weakly below certain levels in the ICM. Therefore, in those models that failed to capture the second cooling in 2011, the thermocline feedback intensity was likely underestimated, which resulted in the predicted SSTs becoming warm in 2011. A detailed comparison between this ICM and other coupled models is clearly needed to explain the differences in depicting the second cooling in 2011. In this regard, the $\mathrm{T}_{e}$ field can be used to diagnose the thermocline feedback intensity.

\section{Methods}

An intermediate coupled model (ICM). The ocean component of the ICM is based on an intermediate complexity mode ${ }^{18}$ that was an extension of the previous, less accurate, baroclinic modal model ${ }^{19}$. The new dynamic ocean model advances the simulations by taking into account spatially varying stratification and partial nonlinear effects in a simplified ocean modeling context; 10 vertical modes are included in the calculation of dynamic ocean fields. This dynamic ocean model allows for realistic simulations of mean equatorial circulation and its variability in the tropical Pacific ${ }^{18}$. An anomaly SST model is incorporated into this intermediate ocean model to represent thermodynamic processes of the surface mixed layer.

Another unique feature added to this ocean model is an empirical parameterization of the temperature of subsurface water entrained in the mixed layer $\left(\mathrm{T}_{\mathrm{e}}\right)^{17}$. As has been clearly demonstrated ${ }^{3}$, the dominant terms controlling the mixed layer heat budget in the equatorial Pacific are vertical mixing and upwelling, whose effects on the SST are sensitively dependent on $\mathrm{T}_{\mathrm{e}}$.

To effectively improve simulations of SST anomalies (SSTAs) in this ocean model, an empirical procedure is developed to parameterize $T_{e}$ in two steps ${ }^{17}$. First, an optimized $\mathrm{T}_{\mathrm{e}}$ field is estimated from the inverse modeling of a given SSTA equation, giving a balanced treatment of various heat budget terms of the mixed layer. Then, a statistical relationship can be constructed using standard statistical analyses during the period $1963-1996^{17}$, from which $\mathrm{T}_{\mathrm{e}}$ can be derived from other ocean dynamic variables (such as sea level) for use in SSTA simulations. This $\mathrm{T}_{\mathrm{e}}$ parameterization is able to capture the nonlocal relationship between $\mathrm{T}_{\mathrm{e}}$ and $\mathrm{SL}$ anomalies in the tropical Pacific and naturally leads to a better depiction of the subsurface effect on SST variability of the mean upwelling of anomalous subsurface temperature anomalies. As such, SSTA simulations are significantly improved in the tropical Pacific. This scheme has been successfully implemented into the ICM for better El Niño simulation and prediction over the tropical Pacific ${ }^{9,10}$. As shown in the main text, the explicit $\mathrm{T}_{\mathrm{e}}$ parameterization based on the relation with SL used in this model enhances its ability to forecast the 2010-11 La Niña events.

Furthermore, the ocean model is coupled with a simple statistical model of interannual wind stress anomalies $\left(\tau_{\text {inter }}\right)$ to form an intermediate coupled model for the tropical Pacific ${ }^{9}$. With reasonable model parameters, the ICM exhibits pronounced interannual variability, which has been extensively analyzed using observational data $^{31}$. In particular, the ICM can realistically depict the spatial structure and time evolution of interannual SST variations associated with ENSO cycles, which provides the basis for SST predictions ${ }^{9,10}$. Since 2003 , this model has been routinely used to predict SST conditions in the tropical Pacific for lead times out to 12 months (cf. some forecast results online at the IRI ENSO web page). In this report, details of the realtime forecasts made during 2010-11 are analyzed.

Observed data. Observational data are required for model prediction and validation during 2010-11. The gridded oceanic temperature and salinity data were obtained from the Argo products provided by the International Pacific Research Center (IPRC)/Asia-Pacific Data-Research Center (APDRC). These data include monthly and long-term climatological mean fields spatially averaged within 1-degree bins. Monthly mixed layer depth (MLD) and $\mathrm{T}_{\mathrm{e}}$ data are also available directly from the IPRC/APDRC Argo products. Gridded sea level anomalies are available online at http://www.aviso.oceanobs.com/duacs/, the Ssalto/Duacs multimission altimeter products distributed by Aviso, with support from Cnes.

As shown in Fig. 1, the structure of $\mathrm{T}_{\mathrm{e}}$ derived from the observation was characterized by a horseshoe-like pattern during 2010-11, with off-equatorial negative $T_{e}$ anomalies merging onto the equator east of the date line, which acted to sustain negative $\mathrm{T}_{\mathrm{e}}$ anomalies on the equator. This $\mathrm{T}_{\mathrm{e}}$ pattern was observed to persist during 2011, whose negative anomalies in the central equatorial domain were responsible for the appearance of a cold SST anomaly to the east in July-August 2011.

A coupled prediction procedure. When using a coupled model for SST forecasts, the consistency among the dynamic model, atmospheric wind fields and initial ocean conditions is critically important ${ }^{20}$. A simple procedure is adopted to initialize model forecasts, in which observed interannual SST anomalies are the only field incorporated into the coupled prediction. In real-time practice, forecasts are usually made around the middle of each month, at a time when the monthly-mean SST data from the previous month and weekly SST data from the first week of the current month become available ${ }^{21}$. Taking the June 2011 prediction as an example, the observed monthly SST fields historically (say from 1980) through May 2011 and weekly SST fields of early June form a temporal succession of daily SST data using a linear interpolation method, from which interannual wind stress anomalies $\left(\tau_{\text {inter }}\right)$ are derived using an empirical mode ${ }^{10}$. The derived $\tau_{\text {inter }}$ fields through early June 2011 are used to force the ocean model to form initial ocean states for the first day of each month (i.e., 1 June 2011), from which forecasts are made. The ocean model produces oceanic fields, including SL anomalies, which are used to determine $\mathrm{T}_{\mathrm{e}}$ fields from the empirical model.

Fig. 1 also presents the SST and $\mathrm{T}_{\mathrm{e}}$ fields on 1 June 2011 simulated from the ICM initialization. One pronounced feature represented in $\mathrm{T}_{\mathrm{e}}$ is a horseshoe-like pattern during 2010-11, with its negative anomaly center located in the central equatorial Pacific, which is sustained by off-equatorial anomalies extending onto the equator in the central domain. Compared with the ARGO-based estimate, the structure of $\mathrm{T}_{\mathrm{e}}$ can be captured well through the ICM initialization procedure (Fig. 2). Using spatial correlations between the observed and predicted data for $\mathrm{SL}$ and $\mathrm{T}_{\mathrm{e}}$, a quantitative evaluation can be made to more clearly demonstrate the $\mathrm{T}_{\mathrm{e}}$ model performance in depicting the relationship between SL and $\mathrm{T}_{\mathrm{e}}$ (figures not given).

Issues with the ICM and its prediction. The ICM we use exhibits obvious discrepancies, which need to be improved upon in the future. For example, the simulated negative $\mathrm{T}_{\mathrm{e}}$ anomalies in the central equatorial basin in 2010-11 are too large; the location of the first appearance of the cold SST anomaly is shifted westward in the model relative to what is observed in nature. Note that in our previous retrospective prediction experiments, the predicted SST anomalies from this model tend to have a cold bias ${ }^{10}$. On the atmospheric side, a simple statistical model is used to empirically derive interannual wind stress variability ${ }^{10}$, which also exhibits some biases, including the simulated easterly wind anomalies that are too weak over the central basin during mid-2011. In addition, as configured, the atmospheric component used in the ICM is based on linear statistical relationships between SST and wind stress, which precludes "atmospheric noise" from outside the equatorial Pacific from influencing the coupled system, thereby implicating ocean nonlinearities in explaining the behavior of the model.

1. Barnston, A. G., Tippett, M. K., L'Heureux, M. L., Li, S. \& DeWitt, D. G. Skill of real-time seasonal ENSO model predictions during 2002-11: Is our capability increasing? Bull. Amer. Meteor. Soc. 93, 631-651 (2012).

2. Cane, M. A., Zebiak, S. E. \& Dolan, S. C. Experimental forecast of El Niño. Nature 321, 827-832 (1986).

3. Zebiak, S. E. \& Cane, M. A. A model El Niño/Southern Oscillation. Mon. Wea. Rev. 115, 2262-2278 (1987).

4. Barnett, T. P., Latif, M., Graham, N., Flugel, M., Pazan, S. \& White, W. ENSO and ENSO-related predictability. Part I: Prediction of equatorial Pacific sea surface temperature with a hybrid coupled ocean-atmosphere model. J. Climate 6, 1545-1566 (1993).

5. Chen, D., Zebiak, S. E., Busalacchi, A. J. \& Cane, M. A. An improved procedure for El Niño forecasting: Implications for predictability. Science 269, 1699-1702 (1995).

6. Ji, M., Leetmaa, A. \& Kousky, V. E. Coupled model forecasts of ENSO during the 1980 and 1990s at the National Meteorological Center. J. Climate 9, 3105-3120 (1996).

7. Latif, M. et al. A review of the predictability and prediction of ENSO. J. Geophys. Res. 103, 14375-14393 (1998). 
8. Kirtman, B., Fan, Y. \& Schneider, E. K. The COLA global coupled and anomaly coupled ocean-atmosphere GCM. J. Climate 15, 2301-2320 (2002).

9. Zhang, R.-H., Zebiak, S. E., Kleeman, R. \& Keenlyside, N. A new intermediate coupled model for El Niño simulation and prediction. Geophys. Res. Lett. 30, 2012 (2003).

10. Zhang, R.-H., Zebiak, S. E., Kleeman, R. \& Keenlyside, N. Retrospective El Niño forecast using an improved intermediate coupled model. Mon. Wea. Rev. 133, 2777-2802 (2005).

11. Saha, S. et al. The NCEP Climate Forecast System. J. Climate 19, 3483-3517 (2006).

12. Zheng, F., Zhu, J., Zhang, R.-H. \& Zhou, G.-Q. Ensemble hindcasts of SST anomalies in the tropical Pacific using an intermediate coupled model. Geophys. Res. Lett. 33, L19604 (2006).

13. Wang, W., Chen, M. \& Kumar, A. An assessment of the CFS real-time seasonal forecasts. Wea. Forecasting 25, 950-969 (2010).

14. Stockdale, T. N. et al. ECMWF seasonal forecast system 3 and its prediction of sea surface temperature. Climate Dyn. 37, 455-471 (2011).

15. Zhu, J., Zhou, G., Zhang, R.-H. \& Sun, Z. Improving ENSO prediction in a hybrid coupled Model with an embedded entrainment temperature parameterization. Int. J. Climatol. (2012).

16. Jin, F. \& An, S. Thermocline and Zonal Advective Feedbacks Within the Equatorial Ocean Recharge Oscillator Model for ENSO. Geophys. Res. Lett. 26, 2989-2992 (1999).

17. Zhang, R.-H., Kleeman, R., Zebiak, S. E., Keenlyside, N. \& Raynaud, S. An empirical parameterization of subsurface entrainment temperature for improved SST simulations in an intermediate ocean model. J. Climate 18, 350-371 (2005).

18. Keenlyside, N. \& Kleeman, R. On the annual cycle of the zonal currents in the equatorial Pacific. J. Geophys. Res. 107 (2002).

19. McCreary, J. P. A linear stratified ocean model of the equatorial undercurrent. Philosophical Transactions of Royal Society (London) 298, 603-635 (1981).

20. McPhaden, M. J., Zebiak, S. E. \& Glantz, M. H. ENSO as an integrating concept in Earth Science. Science 314, 1740-1745 (2006).

21. Reynolds, R. W., Rayner, N. A., Smith, T. M., Stokes, D. C. \& Wang, W. An improved in-situ and satellite SST analysis for climate. J. Climate 15, 1609-1625 (2002).

22. Zhang, R.-H., Rothstein, L. M. \& Busalacchi, A. J. Origin of upper-ocean warming and El Niño change on decadal scale in the tropical Pacific Ocean. Nature 391, 879-883 (1998).

23. Zhang, R.-H. \& Busalacchi, A. J. Interdecadal changes in properties of El Nino in an intermediate coupled model. J. Climate 18, 1369-1380 (2005).

24. Zhang, R.-H., Busalacchi, A. J. \& DeWitt, D. G. The roles of atmospheric stochastic forcing $(S F)$ and oceanic entrainment temperature $\left(T_{e}\right)$ in decadal modulation of ENSO. J. Climate 21, 674-704 (2008).

25. McPhaden, M. J. A 21st century shift in the relationship between ENSO SST and warm water volume anomalies. Geophys. Res. Lett. 39, L09706 (2012).

26. Zhang, R.-H. \& Busalacchi, A. J. Rectified effects of tropical instability wave (TIW)-induced atmospheric feedback in the tropical Pacific. Geophys. Res. Lett. 35, L05608 (2008)
27. Zhang, R.-H. \& Busalacchi, A. J. Freshwater flux (FWF)-induced oceanic feedback in a hybrid coupled model of the tropical Pacific. J. Climate 22, No. 4, 853-879 (2009).

28. Timmermann, A. \& Jin, F.-F. Phytoplankton influences on tropical climate. Geophys. Res. Lett. 29, 2104 (2002).

29. Zhang, R.-H., Busalacchi, A. J., Wang, X., Ballabrera-Poy, J., Murtugudde, R. G., Hackert, E. C. \& Chen, D. Role of ocean biology-induced climate feedback in the modulation of El Niño-Southern Oscillation. Geophys. Res. Lett. 36, L03608 (2009).

30. Collins, M. et al. The impact of global warming on the tropical Pacific Ocean and El Niño. Nature Geoscience 3, 391-397 (2010).

31. Zhang, R.-H. \& Levitus, S. Interannual variability of the coupled Tropical Pacific ocean-atmosphere system associated with the El Nino/Southern Oscillation. J. Climate 10, 1312-1330 (1997).

\section{Acknowledgements}

We would like to thank A. J. Busalacchi, Jiayu Zhou, A. G. Barnston, Dake Chen, Mu Mu, Y. Xue, Z.-Z. Hu and C. Wen for their comments. We benefited greatly from the CPC's ocean briefing for providing real-time diagnostic and prediction discussions for the evolution of the 2010-11 La Niña event; see the summary on the STIP web page made by Jiayu Zhou, which is available online at http://www.nws.noaa.gov/ost/climate/STIP/ $\mathrm{r} 2 \mathrm{o}+\mathrm{o} 2 \mathrm{r}$.htm. This research is supported in part by NSF Grant ATM-0727668, NOAA Grant NA08OAR4310885 and NASA Grants NNX08AI74G, NNX08AI76G and NNX09AF41G. F. Zheng and J. Zhu are supported by the National Basic Research Program of China (Grant No. 2012CB417404) and the Natural Science Foundation of China (Grant No. 41075064); Z. Wang is supported by the National Key Basic Research Program of China (Grant No. 2010CB950303). The authors would like to thank IPRC/APDRC for providing the Argo products, which are available at http://apdrc.soest.hawaii.edu/projects/argo/.

\section{Author contributions}

All authors contributed to extensive and intensive discussions over the years, leading to the central ideas presented in the paper; R.-H. Zhang and F. Zheng contributed to observed data analyses and modeling studies; R.-H. Zhang wrote the paper. All authors reviewed the manuscript.

\section{Additional information}

Competing financial interests: The authors declare no competing financial interests.

License: This work is licensed under a Creative Commons

Attribution-NonCommercial-NoDerivs 3.0 Unported License. To view a copy of this license, visit http://creativecommons.org/licenses/by-nc-nd/3.0/

How to cite this article: Zhang, R.-H., Zheng, F., Zhu, J. \& Wang, Z.G. A successful real-time forecast of the 2010-11 La Niña event. Sci. Rep. 3, 1108; DOI:10.1038/srep01108 (2013). 